\title{
Expand evaluation of the ovarian response prediction index (ORPI) for individualised controlled ovarian stimulation
}

\section{Índice preditor de reserva ovariana (ORPI) para controle de estimulação ovariana individualizado}

\author{
Joao Batista A Oliveira' ${ }^{1,2,3}$, Claudia G Petersen ${ }^{1,2,3}$, Ana L Mauri, ${ }^{1,2}$, Mario Cavagna ${ }^{1,2,4}$ Ricardo LR Baruffi, ${ }^{1,2}$, Jose \\ G Franco Jr', $\mathbf{r}^{1,3}$ \\ ${ }^{1}$ Centre for Human Reproduction Prof. Franco Junior, Preto, Ribeirao, Brazil \\ Accredited Redlara center \\ 2Paulista Centre for Diagnosis, Research and Training, Preto, Ribeirao, Brazil \\ ${ }^{3}$ Department of Gynaecology and Obstetrics, Botucatu Medical School, São Paulo State University, Botucatu, UNESP, Brazil \\ ${ }^{4}$ Women's Health Reference Centre, Perola Byington Hospital, Paulo, Sao, Brazil
}

\begin{abstract}
Objective: to expand the evaluation of a new ovarian response prediction index (ORPI), which was based on the $\mathrm{AMH}, \mathrm{AFC}$ and age, and to verify its reability as a predictor of ovarian response to stimulation in assisted reproductive technology (ART) cycles.

Methods: A total of 129 patients enrolled in the ICSI programme were included. The ORPI values were calculated by multiplying the AMH level $(\mathrm{ng} / \mathrm{ml})$ by the number of antral follicles (2-9 mm), and the result was divided by the age (years) of the patient (ORPI=(AMH $\times$ AFC)/ Patient age).

Results: Spearman's test revealed significant correlations $(P<0.0001)$ between the ORPI and the number of oocytes collected and the number of follicles. Logistic regression revealed that ORPI values were significantly associated with the likelihood of collecting $\geq 4$ oocytes (OR=45.56), $\geq 4$ MII oocytes $(O R=6.01)$ and $\geq 15$ oocytes $(\mathrm{OR}=6.15 ; P<0.0001)$. Based on the ROC curves, the ORPI accurately predicted a low ovarian response ( $<4$ oocytes retrieved; area under the curve (AUC):0.91), collection of $\geq 4$ MII oocytes (AUC:0.85) and an excessive ovarian response ( $\geq 15$ oocytes retrieved; AUC:0.89).

Conclusions: The ORPI exhibited an excellent ability to predict a low ovarian response and a good ability to predict a collection of $\geq 4$ MII oocytes, an excessive ovarian response. The ORPI might be used to improve the cost-benefit ratio of ovarian stimulation regimens by guiding the selection of medications and by modulating the doses and regimens according to the actual needs of the patients.
\end{abstract}

Keywords: Ovarian response prediction index; individualised controlled ovarian stimulation; Anti-Mullerian hormone; Antral follicles; Age

\section{RESUMO}

Objetivo: ampliar a avaliação de um novo índice de previsão de resposta ovariana (ORPI), que foi baseado no $\mathrm{AMH}, \mathrm{AFC}$ e idade, e verificar a sua confiabilidade como um preditor de resposta ovariana à estimulação em tecnologia deciclos de reprodução assistida (ART).
Métodos: Um total de 129 pacientes inscritos no programa de ICSI foram incluídas. Os valores ORPI foram calculados multiplicando-se o nível de $\mathrm{AMH}$ (ng / ml) com o número de folículos antrais (2-9 $\mathrm{mm}$ ), e o resultado foi dividido pela idade (anos) dos pacientes (ORPI $=($ AMH $\times$ AFC) $/$ idade da Paciente $)$. Resultados: testes de Spearman revelaram correlações significativas $(P<0,0001)$ entre o ORPI eo número de oócitos recuperados e o número de folículos. A regressão logística revelou que os valores Orpi foram significativamente associados com a probabilidade de coleta de $\geq 4$ oócitos (OR $=45,56)$, $\geq 4$ oócitos MII (OR $=6,01)$ e $\geq 15$ oócitos (OR $=6,15$, $P<0,0001)$. Com base na curva ROC, O ORPI previu com precisão a resposta ovariana baixa (<4 oócitos recuperados, área sob a curva (AUC): 0,91), a coleta de $\geq 4$ oócitos MII (AUC: 0,85 ) e uma resposta ovariana excessiva ( $\geq 15$ oócitos recuperados; AUC: 0,89). Conclusões: O ORPI exibiu uma excelente capacidade de prever uma resposta ovariana baixa e uma boa capacidade de prever uma coleção de $\geq 4$ oócitos MII, uma resposta ovariana excessiva. O ORPI pode ser utilizado para melhorar a relação custo-benefício dos regimes de estimulação do ovário, orientando a seleção de medicamentos e modulando as doses e regimes de acordo com as reais necessidades das pacientes. Palavras-chave: índice de previsão de respostaovariana; estimulação ovariana controlada individualizada; hormônio anti-mülleriano; folículos antrais; Idade.

\section{INTRODUCTION}

For ovarian stimulation in in vitro fertilisation (IVF) cycles, different protocols have been developed to induce multifollicular development, which increases the number of available oocytes and, thereby, the number of embryos for selection and transfer (Queenan and Whiman-Elia,2000). However, the patients are exposed to the possibility of a low or excessive ovarian response. Furthermore, the possibility of a negative impact of supraphysiological levels of oestrogen resulting from the large numbers of follicles and oocytes on the embryo quality and/or the 
endometrium has been repeatedly questioned (Martinez-Conejero et al.,2007, Rubio et al.,2010). For this reason, knowledge of the patient's potential ovarian response can help clinicians individualise the medication dosage, which may reduce the adverse effects of an excessive ovarian response, decrease the rate of cancelled cycles and ultimately, increase the pregnancy rate.

The first indicator of the ovarian reserve taken into account is the patient's age. Although the number and quality of oocytes both decrease with age, the reproductive potential varies drastically among women of similar age (Alviggi et al.,2012). In fact, in addition to age, several clinical, endocrine and ultrasound markers, and dynamic tests have been proposed for the prediction of the ovarian response to stimulation (Broekmans et al.,2006, La Marca et al.,2012). Among these markers, use of the level of anti-Müllerian hormone (AMH) and the antral follicle count (AFC) is of particular interest (Broekmans et al.,2006, Hendriks et al.,2005, Jayaprakasan et al.,2010, La Marca et al.,2009,2011,2012, Lekamge et al.,2007, Nelson et al.,2012, Yovich et al.,\2012).

However, despite the predictive power that each marker for the ovarian response may have individually, all of these markers have errors associated with their estimation. In fact, none of these parameters can be considered to be undoubtedly reliable predictors of the number/quality of the remaining oocytes in the ovary or the probability of pregnancy following infertility treatment (ASRM,2012, Younis et al.,2010). A systematic review of tests predicting the ovarian reserve and IVF outcomes (Broekmans et al.,2006) observed that the accuracy of the so-called ovarian reserve tests in predicting the occurrence of both a poor ovarian response and hyperstimulation appears to be modest. Therefore, a prediction of the ovarian response using a single biomarker may not be sufficient for the formulation of a precise treatment plan.

Considering these observations, the main objective of the present study was to expand the evaluation of a new ovarian response prediction index (ORPI), which was based on the AMH, AFC and age, and to verify its reability as a predictor of ovarian response to stimulation in assisted reproductive technology (ART) cycles.

\section{METHODS \\ Patients}

This study included 129 patients attending their first IVF/ICSI (intracytoplasmic sperm injection) cycle. All patients satisfied the following criteria: age $\leq 39$ years, body mass index (BMI) between $20-30 \mathrm{~kg} / \mathrm{m}^{2}$, regular menstrual cycles, both ovaries present, no history of ovarian surgery, no severe endometriosis and no evidence of endocrine disorders. The only exclusion criterion was the presence of ovarian cysts as assessed by transvaginal ultrasound.

\section{AMH measurement}

A venous blood sample for an $\mathrm{AMH}$ measurement was taken before the scheduled treatment (minimum of 30 days) during the early follicular menstrual cycle phase in all women. AMH was measured using an enzymatically amplified 2-site immunoassay kit (AMH Gen II ELISA, Beckman Coulter Inc.) according to the manufacturer's manual. The lowest detection limit of this assay is 0.01 $\mathrm{ng} / \mathrm{ml}$, whereas the maximum intra- and inter-assay coefficients of variation are $3.3 \%$ and $6.5 \%$, respectively. To minimise the chances of bias in the assay, all sera were processed in duplicate during the same day, using the same measurement kits, and by the same operator. Low- and high-level controls were included in each assay.

\section{Antral follicles count}

All subjects had a transvaginal ultrasonographic evaluation performed during the early follicular phase of a previous cycle before the scheduled treatment. A single experienced sonographer, who was blinded to the results of any hormonal assays and the patient's age, performed the evaluation using I transvaginal ultrasound at $7 \mathrm{MHz}$. The total number of 2-9mm antral follicles in both ovaries was used for the calculations. The intra-observer coefficient of variation was $1.0 \%$.

\section{Ovarian stimulation protocol}

The patients were subjected to 2 schemes of controlled ovarian stimulation, as follows: a long gonadotropin-releasing hormone $(\mathrm{GnRH})$ agonist $(\mathrm{GnRH}-\mathrm{a} / \mathrm{n}=73)$ protocol or a multi-dose $\mathrm{GnRH}$ antagonist ( $\mathrm{GnRH}$-ant/n=56) protocol. The selection of the stimulation protocol was at the discretion of the clinician.

GnRH-a protocol: The pituitary downregulation began during the luteal phase of the previous menstrual cycle with the GnRH-a leuprolide acetate (leuprolide acetate; Lupron ${ }^{\circledR}$; Abbott) at a dose of $1 \mathrm{mg} /$ day for 14 days. The ovaries were then stimulated with a fixed dose of 150-225IU of recombinant FSH ( $r F S H$; Gonal $\mathrm{F}^{\circledR}$; Serono) and $75 \mathrm{IU} /$ day of recombinant luteinising hormone (rLH; Luveris ${ }^{\circledR}$; Serono) for a period of 7 days. The decision on the starting dose of FSH was based on patient's age. On day 8 of the ovarian stimulation, the follicular development was monitored by a transvaginal ultrasound at $7 \mathrm{MHz}$. The rFSH dose was modified according to the ovarian response, and the rLH supplementation was increased to $150 I U /$ day when one or more follicles measuring $\geq 10 \mathrm{~mm}$ in diameter were found.

GnRH-ant protocol: On day 3 of the cycle, ovarian stimulation was induced with a fixed dose of 150-225IU of rFSH and $75 \mathrm{IU} /$ day of rLH for a period of 5 days. The decision on the starting dose of FSH was based on patient's age. On day 8 of the menstrual cycle (day 6 of ovarian stimulation), the follicular development was monitored by a transvaginal ultrasound at $7 \mathrm{MHz}$. The r-FSH dose was modified according to the ovarian response, and the $\mathrm{r}$-LH supplementation was increased to $150 \mathrm{IU} /$ day when 1 or more follicles measuring $\geq 10 \mathrm{~mm}$ in diameter were found. The $\mathrm{GnRH}$-ant cetrorelix (cetrorelix; Cetrotide ${ }^{\circledR}$; Serono) was started at a dose of $0.25 \mathrm{mg} /$ day s.c. when at least 1 follicle of $\geq 14 \mathrm{~mm}$ was observed by the ultrasound.

To induce the final oocyte maturation in both protocols

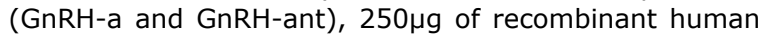
chorionic gonadotropin ( $\mathrm{r}$-hCG; Ovidrel; Serono) was administered S.c. when at least 2 follicles reached a mean diameter of $\geq 17 \mathrm{~mm}$. GnRH-a and $\mathrm{GnRH}$-ant were administered until the day of the r-hCG injection. The oocyte retrieval was performed by a transvaginal aspiration under ultrasound guidance 34-36 hours following the r-hCG injection.

\section{Calculation of ovarian response prediction index (ORPI)}

The ORPI values were calculated by multiplying the AMH $(\mathrm{ng} / \mathrm{ml})$ level by the number of antral follicles (2-9 $\mathrm{mm}$ ), and the result was divided by the age (years) of the patient. This definition of ORPI was based on previous evaluations that found that the ovarian response to stimulation had positive correlations with the $\mathrm{AMH}$ levels and number of antral follicles and was negatively correlated with the patient's age. The derivation of ORPI was intuitive, based on the observed correlations and testing of different combinations. We sought a simple index that was easy to use in daily practice and combi- 
ned a small number of variables whose association could potentiate the result of each individual variable in predicting ovarian response to stimulation and at the same time compensate for possible individual deficiencies. The ORPI was defined by the following equation: ORPI $=($ AMH $\times$ AFC $) /$ Patient age.

Notably, the calculated value of the ORPI in the study was not influenced by the protocol choice for the induction of ovulation or the doses of gonadotropin.

\section{Endpoints}

The primary endpoints were the total number of oocytes and the number of metaphase II (MII) oocytes retrieved. The secondary endpoints were the number of follicles $\geq 10 \mathrm{~mm}, \geq 16 \mathrm{~mm}$ and $\geq 18 \mathrm{~mm}$ on the day of HCG administration.

\section{Statistical analysis}

The values for the ORPI, age, AMH, AFC, total number of oocytes retrieved, number of MII oocytes and the number of follicles $\geq 10 \mathrm{~mm}, \geq 16 \mathrm{~mm}$ and $\geq 18 \mathrm{~mm}$ on the day of hCG administration were treated as continuous variables for analysis. The Mann-Whitney test, Student's t-test and the chi-square test were used when appropriate. Correlations were performed using the Spearman's rank correlation test. A $\mathrm{P}<0.05$ was considered statistically significant.

A univariate logistic regression was used to estimate the value of an independent variable in predicting the likelihood of collecting $\geq 4$ oocytes (criterion for the classification as a poor ovarian response) (Ferraretti et al.,2011, Rombauts et al.,2011, Younis et al.,2010), collecting $\geq 4$ MII oocytes and collecting $\geq 15$ oocytes (assessing excessive response) (Broer et al.,2011, Ebner et al.,2006, Riggs et al.,2008). The odds ratio (OR) and $95 \%$ confidence interval (CI) constituted the descriptive analysis.

Receiver operating characteristic (ROC) curves were constructed to examine the performance of the ORPI in predicting the retrieval of $\geq 4$ oocytes, $\geq 4$ MII oocytes and $\geq 1500$ cytes. An optimised threshold was determined. The discriminative performance of the model was assessed by the area under the curve (AUC) of the ROC curve.

\section{RESULTS}

The general characteristics of the study population are summarised in Table 1 . Of all 129 women, the mean age was 34.5 \pm 4.8 years (range 21-39), the mean AMH level was $1.8 \pm 1.8 \mathrm{ng} / \mathrm{mL}$ (range $0.01-9.6$ ) and

Table 1. General characteristics of the study population

\begin{tabular}{|c|c|c|c|c|}
\hline & $\begin{array}{c}\text { General population } \\
(n=129)\end{array}$ & $\begin{array}{l}\text { GnRH agonist protocol } \\
(n=73)\end{array}$ & $\begin{array}{l}\text { GnRH antagonist protocol } \\
(\mathbf{n = 5 6 )}\end{array}$ & $\boldsymbol{P}$ \\
\hline Age (years) & $\begin{array}{c}34.5 \pm 4.8 \\
(21-39)\end{array}$ & $\begin{array}{c}34.6 \pm 5.2 \\
(21-39)\end{array}$ & $\begin{array}{c}34.3 \pm 4.3 \\
(26-39)\end{array}$ & 0.70 \\
\hline AMH (ng/ml) & $\begin{array}{c}1.8 \pm 1.8 \\
(0.01-9.6)\end{array}$ & $\begin{array}{c}1.5 \pm 1.3 \\
(0.01-8.2)\end{array}$ & $\begin{array}{c}2.1 \pm 2.1 \\
(0.01-9.6)\end{array}$ & 0.33 \\
\hline AFC (n) $(2-9 \mathrm{~mm})$ & $\begin{array}{c}12.1 \pm 6.0 \\
(2-34)\end{array}$ & $\begin{array}{c}11.4 \pm 5.3 \\
(2-34)\end{array}$ & $\begin{array}{c}13.1 \pm 6.7 \\
(4-28)\end{array}$ & 0.24 \\
\hline ORPI & $\begin{array}{c}1.0 \pm 1.4 \\
(0-8.8)\end{array}$ & $\begin{array}{c}0.7 \pm 1.1 \\
(0-8.8)\end{array}$ & $\begin{array}{l}1.2 \pm 1.7 \\
(0-7.6)\end{array}$ & 0.30 \\
\hline BMI & $24.4 \pm 4.6$ & $24.0 \pm 5.0$ & $25.1 \pm 3.9$ & 0.19 \\
\hline Tobacco use & $3.9 \%(5 / 129)$ & $2.7 \%(2 / 73)$ & $5.3 \%(3 / 56)$ & 0.76 \\
\hline Regular alcohol use & $2.3 \%(3 / 129)$ & $1.4 \%(1 / 73)$ & $3.6 \%(2 / 56)$ & 0.81 \\
\hline Time of infertility (years) & $4.7 \pm 3.6$ & $5.1 \pm 4.0$ & $4.1 \pm 2.8$ & 0.14 \\
\hline $\begin{array}{l}\text { Aetiology }(\%) \\
\text { Male } \\
\text { Idiopathic } \\
\text { Tuboperitoneal } \\
\text { Endometriosis } \\
\text { Tuboperitoneal+endometriosis } \\
\text { Male+endometriosis } \\
\text { Male+tuboperitoneal }\end{array}$ & $\begin{array}{c}36.4 \%(47 / 129) \\
26.4 \%(34 / 129) \\
17.8 \%(23 / 129) \\
13.2 \%(17 / 129) \\
3.1 \%(4 / 129) \\
2.3 \%(3 / 129) \\
0.8 \%(1 / 129)\end{array}$ & $\begin{array}{c}41.1 \%(30 / 73) \\
20.5 \%(15 / 73) \\
17.8 \%(13 / 73) \\
15.1 \%(11 / 73) \\
2.7 \%(2 / 73) \\
1.4 \%(1 / 73) \\
1.4 \%(1 / 73)\end{array}$ & $\begin{array}{c}30.4 \%(17 / 86) \\
33.3 \%(19 / 56) \\
17.8 \%(10 / 56) \\
10.7 \%(6 / 56) \\
3.6 \%(2 / 56) \\
3.6 \%(2 / 56) \\
0(0 / 56)\end{array}$ & 0.26 \\
\hline Total dose FSH (UI) & $1983 \pm 806$ & $2106 \pm 768$ & $1743 \pm 796$ & 0.34 \\
\hline Total dose LH (UI) & $989 \pm 343$ & $1014 \pm 316$ & $956 \pm 376$ & 0.60 \\
\hline Time of stimulation (days) & $10.0 \pm 2.1$ & $10.4 \pm 2.1$ & $9.5 \pm 1.9$ & 0.21 \\
\hline $\begin{array}{l}\text { Follicles (n) (hCG day) } \\
\geq 10 \mathrm{~mm} \\
\geq 16 \mathrm{~mm} \\
\geq 18 \mathrm{~mm}\end{array}$ & $\begin{array}{l}12.4 \pm 8.3 \\
5.7 \pm 3.5 \\
3.8 \pm 2.5\end{array}$ & $\begin{array}{l}12.3 \pm 7.3 \\
6.2 \pm 3.6 \\
4.1 \pm 2.3\end{array}$ & $\begin{array}{l}12.5 \pm 9.5 \\
4.9 \pm 3.4 \\
3.3 \pm 2.6\end{array}$ & $\begin{array}{l}0.62 \\
0.26 \\
0.88\end{array}$ \\
\hline $\begin{array}{l}\text { Retrieved oocytes } \\
\text {-Total } \\
\text {-Metaphase II stage } \\
\text {-Metaphase I stage } \\
\text {-Germinal vesicle stage }\end{array}$ & $\begin{array}{l}9.3 \pm 6.8 \\
6.6 \pm 5.0 \\
1.2 \pm 1.7 \\
0.8 \pm 1.1\end{array}$ & $\begin{array}{l}9.4 \pm 6.1 \\
6.7 \pm 4.6 \\
1.2 \pm 1.6 \\
0.8 \pm 1.2\end{array}$ & $\begin{array}{l}9.2 \pm 7.7 \\
6.4 \pm 5.6 \\
1.3 \pm 1.9 \\
0.7 \pm 1.0\end{array}$ & $\begin{array}{l}0.48 \\
0.36 \\
0.74 \\
0.95\end{array}$ \\
\hline
\end{tabular}

AMH: anti-mullerian hormone

ORPI: ovarian response prediction index

AFC: antral folicle count 
Table 2. Correlation between predictors of the ovarian response (age, AMH, AFC and ORPI) and the total number of oocytes collected, total number of MII oocytes collected and the number of follicles $\geq 10 \mathrm{~mm}, \geq 16 \mathrm{~mm}$ and $\geq 18 \mathrm{~mm}$ at the time of hCG administration

\begin{tabular}{|c|c|c|c|}
\hline \multirow[t]{2}{*}{ Ovarian response markers } & \multicolumn{3}{|c|}{ Total oocytes retrivaled } \\
\hline & $r$ & $95 \%$ confidence interval & $P$ \\
\hline Age & -0.47 & -0.59 to -0.31 & $<0.0001$ \\
\hline AMH & 0.72 & 0.61 to 0.79 & $<0.0001$ \\
\hline AFC & 0.68 & 0.57 to 0.76 & $<0.0001$ \\
\hline ORPI & 0.76 & 0.68 to 0.83 & $<0.0001$ \\
\hline \multirow[t]{2}{*}{ Ovarian response markers } & \multicolumn{3}{|c|}{ MII oocytes } \\
\hline & $r$ & $95 \%$ confidence interval & $P$ \\
\hline Age & -0.48 & -0.60 to -0.33 & $<0.0001$ \\
\hline AMH & 0.66 & 0.54 to 0.75 & $<0.0001$ \\
\hline AFC & 0.61 & 0.49 to 0.71 & $<0.0001$ \\
\hline ORPI & 0.70 & 0.59 to 0.78 & $<0.0001$ \\
\hline \multirow[t]{2}{*}{ Ovarian response markers } & \multicolumn{3}{|c|}{ Follicles $\geq 10 \mathrm{~mm}$} \\
\hline & $r$ & $95 \%$ confidence interval & $P$ \\
\hline Age & -0.44 & -0.57 to -0.29 & $<0.0001$ \\
\hline AMH & 0.77 & 0.69 to 0.84 & $<0.0001$ \\
\hline AFC & 0.73 & 0.64 to 0.81 & $<0.0001$ \\
\hline ORPI & 0.81 & 0.74 to 0.87 & $<0.0001$ \\
\hline \multirow[t]{2}{*}{ Ovarian response markers } & \multicolumn{3}{|c|}{ Follicles $\geq 16 \mathrm{~mm}$} \\
\hline & $r$ & $95 \%$ confidence interval & $P$ \\
\hline Age & -0.41 & -0.54 to -0.24 & $<0.0001$ \\
\hline AMH & 0.61 & 0.49 to 0.71 & $<0.0001$ \\
\hline AFC & 0.57 & 0.43 to 0.67 & $<0.0001$ \\
\hline ORPI & 0.65 & 0.53 to 0.74 & $<0.0001$ \\
\hline \multirow[t]{2}{*}{ Ovarian response markers } & \multicolumn{3}{|c|}{ Follicles $\geq 18 \mathrm{~mm}$} \\
\hline & $r$ & 95\% confidence interval & $P$ \\
\hline Age & -0.35 & -0.49 to -0.19 & $<0.0001$ \\
\hline AMH & 0.51 & 0.34 to 0.63 & $<0.0001$ \\
\hline AFC & 0.48 & 0.34 to 0.61 & $<0.0001$ \\
\hline ORPI & 0.54 & 0.40 to 0.65 & $<0.0001$ \\
\hline
\end{tabular}

AMH: anti-mullerian hormone

ORPI: ovarian response prediction index

AFC: antral folicle count

the mean AFC was $12.1 \pm 6.0$ (range 2-34). The mean ORPI was $1.0 \pm 1.4$ (range $0-8.8$ ). Basic demographic characteristics such as age, BMI, duration of infertility, smoking, alcohol use and infertility aetiology were not significantly different $(P>0.05)$ between the $\mathrm{GnRH}-\mathrm{a}$ and $\mathrm{GnRH}$-ant patient groups. The distribution $(P>0.05)$ of the main characteristics of the ovarian stimulation cycle observed for the $\mathrm{GnRH}-\mathrm{a}$ and $\mathrm{GnRH}-$ -ant groups were comparable.

The regression analysis demonstrated significant $(P<0.05)$ positive correlations between the ORPI and the total number of oocytes collected $(r=0.76)$, total number of MII oocytes $(r=0.70)$ and the number of follicles $\geq 10 \mathrm{~mm}(r=0.81)$, follicles $\geq 16 \mathrm{~mm}(r=0.65)$ and follicles $\geq 18 \mathrm{~mm}$ ( $r=0.54$ ) on the hCG administration day. Additionally, all the other markers of ovarian response showed statistically significant correlations with the variables analysed. However, the association provided by the ORPI improved the correlation because the individual correlation coefficients of each marker of ovarian response (age, AMH and AFC) were always lower than that presented by the ORPI. Table 2 summarises these results.
The logistic regression analysis revealed that the ORPI values were significantly associated with the likelihood of collecting $\geq 400$ cytes (OR: 45.56; $P<0.0001$ ), $\geq 4$ metaphase II oocytes (OR:6.01; $P<0.0001$ ) and $\geq 1500$ cytes (OR:6.15; $P<0.0001$ ). Alternatively, the logistic regression analysis also revealed a statistically significant $(P<0.05)$ association between the number and maturity of collected oocytes and the other prognostic factors analysed (woman's age, AMH and AFC). However, the odds ratios presented by the ORPI were always higher (i.e., further from 1 ) than those presented by all other prognostic factors. The results indicate that for each one unit increase of the ORPI value, the chance of collecting $\geq 400$ cytes increases 45 times (or it increases by 4.5 times for each increase of 0.1 ) and 6 times for collecting $\geq 4$ MII oocytes $\geq 15$ oocytes. These results indicate that the ORPI presents a predictive capability for the occurrence of these events (collection of $\geq 400$ cytes, $\geq 4$ MII oocytes and $\geq 1500$ cytes) that was higher than that of each marker individually. Figure 1 summarises these results.

The performance of the ORPI as a prognostic test was observed using ROC curves (Figure 2). Regarding the 
Table 3. The deployment of the ovarian stimulation protocol and doses of follicle-stimulating hormone (FSH) in the groups categorised by the ovarian response prediction index (ORPI)

\begin{tabular}{llll}
\hline $\begin{array}{l}\text { ORPI } \\
\text { values }\end{array}$ & $\begin{array}{l}\text { Oocyte } \\
\text { number } \\
\text { (expected) }\end{array}$ & Protocol & $\begin{array}{l}\text { Dose of } \\
\text { FSH }\end{array}$ \\
\hline preg<0.2 & $\leq 3$ & $\begin{array}{l}\text {-GnRH Antagonist } \\
\text {-Short GnRH Agonist } \\
\text {-Clomiphene citrate } \\
\text { + FSH } \\
\text {-Long GnRH Agonist }\end{array}$ & $\begin{array}{l}300 \\
\text { IU-150 } \\
\text { IU }\end{array}$ \\
\hline$\geq 0.2-<0.5$ & $4-5$ & $\begin{array}{l}\text {-GnRH Antagonist } \\
\text {-Short GnRH Agonist } \\
\text {-Long GnRH Agonist }\end{array}$ & $\begin{array}{l}300 \\
\text { IU-150 }\end{array}$ \\
\hline$\geq 0.5-<0.9$ & $6-14$ & $\begin{array}{l}\text {-Long GnRH Agonist } \\
\text {-GnRH Antagonist }\end{array}$ & $\begin{array}{l}150 \\
\text { IU-112.5 }\end{array}$ \\
& & IU \\
\hline$\geq 0.9$ & $\geq 15$ & -GnRH Antagonist & 112.5 \\
& & & IU-75 IU \\
\hline
\end{tabular}

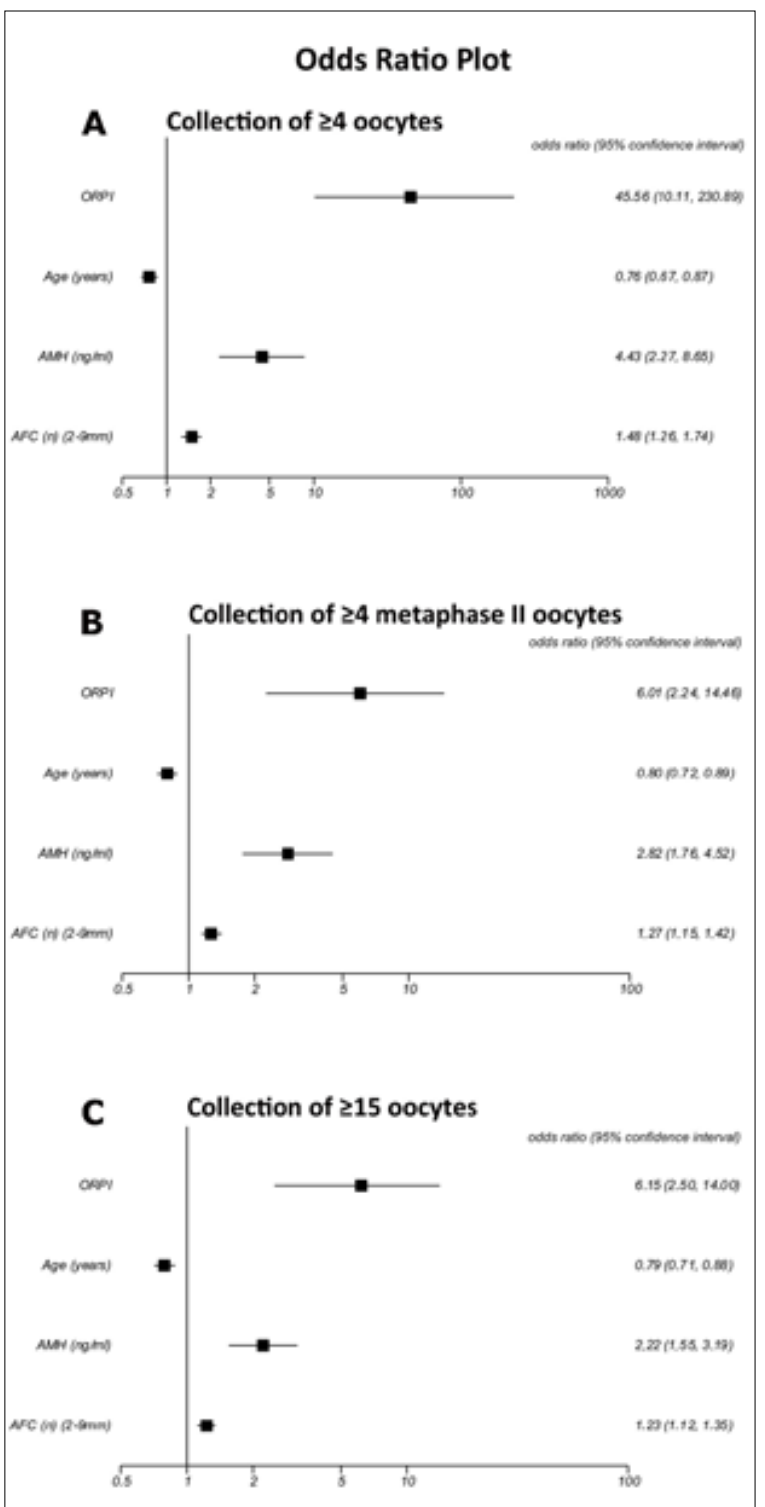

Figure 1. Logistic regression analysis for the prognostic factors regarding the collected oocytes. A. Collection of $\geq 4$ oocytes. B. Collection of $\geq 4$ MII oocytes. C. Collection of $\geq 15$ oocytes.

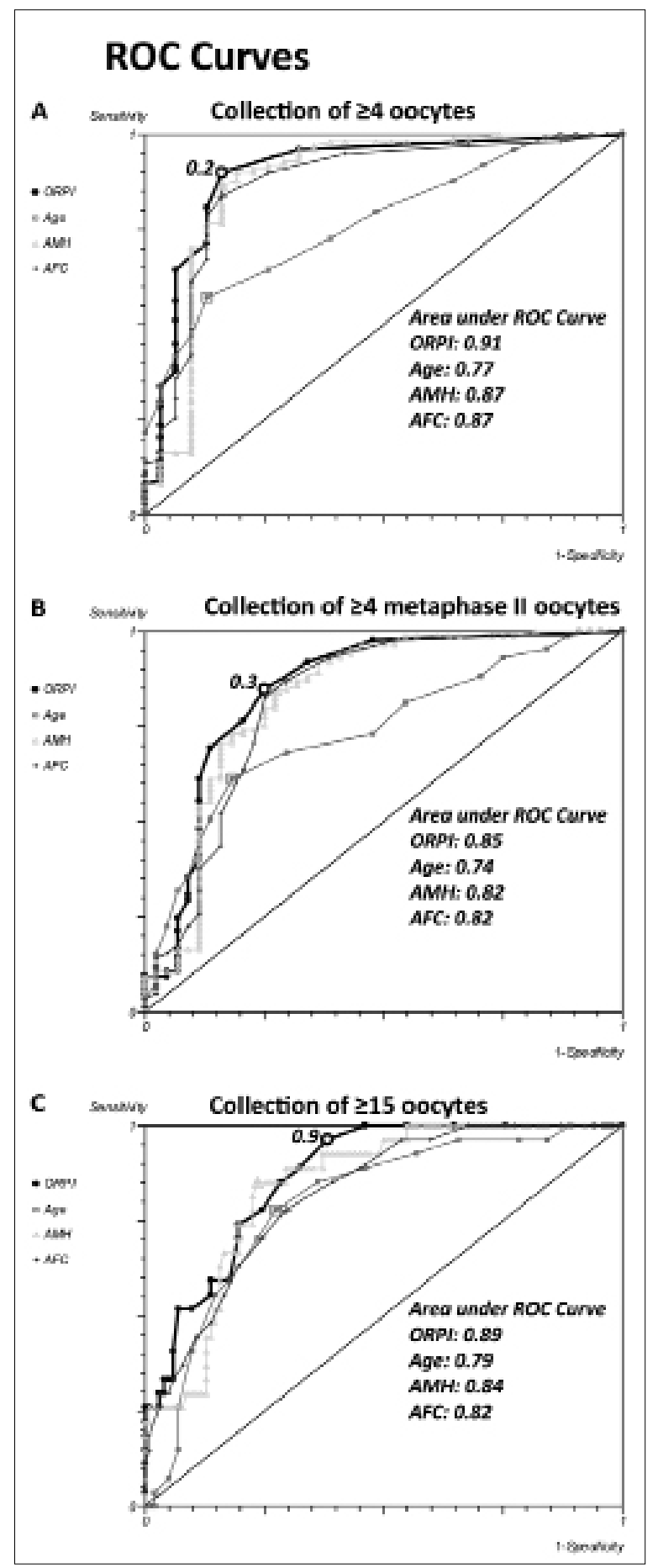

Figure 2. ROC Curve. The ROC curve analysis for ORPI as a prognostic factor regarding the collected oocytes. A. Collection of $\geq 4$ oocytes. B. Collection of $\geq 4$ metaphase II (MII) oocytes. C. Collection of $\geq 15$ oocytes.

probability of collecting $\geq 4$ oocytes, the ROC curve showed an area under the curve of 0.91 (95\% CI: $0.82-0.97$ ), indicating that the ORPI had an excellent prognostic potency for this point. Setting the threshold at 0.2 offered the optimal compromise between specificity ( $83 \%)$ and sensitivity ( $89 \%)$ and between positive predictive value $(95 \%)$ and negative predictive value $(72 \%)$. At this cut-off level, the efficacy of the ORPI for collecting at least 4 oocytes was 
$88 \%$. Similarly, in regards to the probability of collecting $\geq 4$ MII oocytes, the ROC curve had an area under the curve of 0.85 ( $95 \% \mathrm{CI}: 0.77-0.93$ ), indicating that the ORPI also had a good prognostic potency for this issue. Setting the threshold at 0.3 offered the optimal compromise between specificity $(75 \%)$ and sensitivity $(85 \%)$ and between positive predictive value $(87 \%)$ and negative predictive value $(72 \%)$. At this cut-off level, the efficacy of the ORPI for retrieval of at least 4 MII oocytes was $81 \%$. In the same way, the ROC curve for the probability of collecting $\geq 15$ oocytes gave an area under the curve of 0.89 (95\% CI: 0.81-0.92), indicating that the ORPI values in this situation had a good prognostic potency. Setting the threshold at 0.9 offered the optimal compromise between specificity $(87 \%)$ and sensitivity $(83 \%)$ and between positive predictive value (92\%) and negative predictive value $(68 \%)$. At this cut-off level, the efficacy of the ORPI for collecting $\geq 15$ oocytes was $82 \%$.

The ROC curves also revealed good prognostic potency for all other factors (Age, AMH and AFC) analysed regarding the probability of collecting $\geq 4$ oocytes, collecting $\geq 4$ MII oocytes or collecting $\geq 15$ oocytes. However, the AUC presented by the ORPI was always higher than those presented by all others. Figure 2 shows these data

\section{DISCUSSION}

A reliable indicator for supplying more precise estimates of the patients' ovarian response might facilitate the optimisation and individualisation of assisted reproductive treatment before the onset of a treatment cycle. The present study proposes a new index, the ORPI, to identify the probable ovarian response to stimulation during the ART cycles. The combination of different variables in the ORPI resulted in a more precise index to predict the ovarian response. Indeed, the results showed significant correlations $(P<0.001)$ between the ORPI values and the number of obtained follicles and the number and maturity of the collected oocytes. In addition, the results using the ORPI were always better than those results obtained using other predictive factors (AFC, AMH and age) separately. These findings support the use of this simple 3 -variable index.

To the best of our knowledge, the present study is the first to combine those 3 factors into one single index for the assessment of the ovarian reserve.

An estimate based solely on age is not always sufficient to accurately predict the ovarian response to gonadotropin stimulation, considering that the ovarian response is highly variable even among women of a similar age. This inter-individual variation depends on the ovarian reserve of each person, which is influenced by genetic and environmental factors that primarily determine the size of the pool of primordial follicles at birth and the rate of the pool's decline throughout the reproductive life (Nikolaou and Templeton,2003). In addition, the number of antral follicles can be assessed during a routine pelvic ultrasound examination, which is an integral part of the pretreatment assessment of women undergoing any assisted reproduction treatment in almost all fertility units. Therefore, an ultrasound evaluation of the antral follicles has gained acceptance as a good predictor of the ovarian response with low intra- and inter-observer variations (Hendriks et al.,2005), despite its routine use being hampered by the lack of a standard methodology that would enable valid data comparisons between different centres (Alviggi et al.,2012, Broekmans et al.,2010). Based on these observations, a joint analysis of age and the AFC might combine their advantages and compensate for their disadvantages, thus improving the assessment of ovarian function. Indeed, upon attempting to develop prognostic models for the identification of patients' ovarian response, la Cour Freiesleben et al. (2011) found that the best prognostic model to predict a low response included AFC and age.

In addition, the prediction of the ovarian response could be further improved by including the serum AMH levels into the calculation of the ORPI. Despite this test not being universally available and recent alterations in the methodology (La Marca et al.,2009, Nelson et al.,2012, Nelson and La Marca,2011), the determination of the AMH level consists of a simple blood test that can be performed at any time during the menstrual cycle (La Marca et al.,2010, van Disseldorp et al.,2010). In contrast to the levels of FSH, LH and oestradiol, the levels of AMH throughout the menstrual cycle show no consistent fluctuation patterns (Fanchin et al.,2003). Moreover, the random fluctuations were small, indicating that $\mathrm{AMH}$ can be used as a reliable and cycle-independent marker for the ovarian reserve (La Marca et al.,2006, Nelson et al.,2012). AMH appears to have a strong association with the ovarian response to stimulation, as shown by several authors (Broer et al.,2011,2009, Jayaprakasan et al.,2010, Nakhuda et al., 2010, Nelson et al.,2009, Wang et al.,2010, Yates et al.,2011), and it was eventually suggested for use in individualising the regimens for ovulation stimulation based on the AMH values (Ebner et al.,2006, Riggs et al.,2008). In 2 meta-analyses, Broer et al. $(2011,2009)$ found that AMH exhibits the same level of precision as the AFC for predicting poor ovarian response and excessive responders to ovarian stimulation. Jayaprakasan et al. (2010) emphasised that $\mathrm{AMH}$ and AFC might replace each other as the best predictors of a poor ovarian response.

The simplicity of the calculation, which requires clinicians to perform simple mathematical operations using the variable values directly, and a direct correlation with the results are the major strong points of the ORPI. Other published studies also aimed to assess the ovarian response by combining variables (la Cour Freiesleben et al.,2011, Lekamge et al.,2007, Muttukrishna et al.,2005, Younis et al.,2010, Yovich et al.,2012). However, either these formulas were too complex compared to the simplicity of the ORPI (Lekamge et al.,2007, Spencer et al.,2010)] or a wide variety of variables were included, which made the assessment complex (Younis et al.,2010, Yovich et al.,2012). Other studies (Biasoni et al.,2011, Gallot et al.,2012) described an index whose calculation required at least 1 cycle of treatment. Conversely, another advantage of the ORPI is its ability to estimate the ovarian response before the onset of any treatment.

There is no conventional ovarian stimulation regimen universally useful for every single patient. Based on its predictive potential, the ORPI might be used as a tool in the individualised planning of the medication doses and/or ovarian stimulation regimens. Based on the cut-off points obtained by the ROC curve analysis, we suggest several stimulation regimens grounded on the results of the ORPI. Table 3 summarises these stimulation protocols and the FSH doses to be used according to the range of calculated ORPI values with a particular focus on the extreme points of the ovarian response. 


\section{CONCLUSION}

To summarise, the present study reinforce the ORPI, which is a simple 3-variable index that exhibits an excellent ability to predict a low ovarian response (AUC: 0.91 ) and a good ability to predict the collection of >4 MII oocytes (AUC: 0.84 ) and an excessive ovarian response (AUC: 0.89 ) in infertile women. The ORPI might be used to improve the cost-benefit ratio of ovarian stimulation regimens by guiding the selection of medications and by tailoring the doses and regimens to the actual needs of patients.

\section{Corresponding author:}

J.G. Franco Jr

Centre for Human Reproduction Prof. Franco Junior

Avenida Prof. João Fiusa, 689-CEP 14025-310

Ribeirão Preto - SP - Brazil

Phone: 551639111100

FAX: 551639111100

E-mail: crh@crh.com.br

Support: None

\section{REFERENCES}

Alviggi C, Humaidan P, Ezcurra D. Hormonal, functional and genetic biomarkers in controlled ovarian stimulation: tools for matching patients and protocols. RB\&E. 2012;10:9.

ASRM. Diagnostic evaluation of the infertile female: a committee opinion. Fertil steril. 2012;98:302-7.

Biasoni V, Patriarca A, Dalmasso P, Bertagna A, Manieri C, Benedetto $C$, Revelli A. Ovarian sensitivity index is strongly related to circulating $\mathrm{AMH}$ and may be used to predict ovarian response to exogenous gonadotropins in IVF. RB\&E. 2011;9:112.

Broekmans FJ, de Ziegler D, Howles CM, Gougeon A, Trew G, Olivennes F. The antral follicle count: practical recommendations for better standardization. Fertil steril. 2010;94:1044-51.

Broekmans FJ, Kwee J, Hendriks DJ, Mol BW, Lambalk CB. A systematic review of tests predicting ovarian reserve and IVF outcome. Hum Reprod Update. 2006;12:685-718.

Broer SL, Dolleman M, Opmeer BC, Fauser BC, Mol BW, Broekmans FJ. AMH and AFC as predictors of excessive response in controlled ovarian hyperstimulation: a meta-analysis. Hum Reprod Update. 2011;17:46-54.

Broer SL, Mol BW, Hendriks D, Broekmans FJ. The role of antimullerian hormone in prediction of outcome after IVF: comparison with the antral follicle count. Fertil steril. 2009;91:705-14.

Ebner T, Sommergruber M, Moser M, Shebl O, Schreier-Lechner E, Tews G. Basal level of anti-Mullerian hormone is associated with oocyte quality in stimulated cycles. Hum reprod. 2006;21:2022-6.

Fanchin R, Schonauer LM, Righini C, Guibourdenche J, Frydman R, Taieb J. Serum anti-Mullerian hormone is more strongly related to ovarian follicular status than serum inhibin $\mathrm{B}$, estradiol, $\mathrm{FSH}$ and $\mathrm{LH}$ on day 3. Hum reprod. 2003;18:323-7.

Ferraretti AP, La Marca A, Fauser BC, Tarlatzis B, Nargund G, Gianaroli L. ESHRE consensus on the definition of 'poor response' to ovarian stimulation for in vitro fertilization: the Bologna criteria. Hum reprod. $2011 ; 26: 1616-24$

Gallot V, Berwanger da Silva AL, Genro V, Grynberg M, Frydman $\mathrm{N}$, Fanchin R. Antral follicle responsiveness to follicle-stimulating hormone administration assessed by the Follicular Output RaTe (FORT) may predict in vitro fertilization-embryo transfer outcome. Hum reprod. 2012;27:1066-72.

Hendriks DJ, Mol BW, Bancsi LF, Te Velde ER, Broekmans FJ. Antral follicle count in the prediction of poor ovarian response and pregnancy after in vitro fertilization: a meta-analysis and comparison with basal follicle-stimulating hormone level. Fertil steril. 2005;83:291-301.

Jayaprakasan K, Campbell B, Hopkisson J, Johnson I, Raine-Fenning $\mathrm{N}$. A prospective, comparative analysis of anti-Mullerian hormone, inhibin- $B$, and three-dimensional ultrasound determinants of ovarian reserve in the prediction of poor response to controlled ovarian stimulation. Fertil steril. 2010;93:855-64.

la Cour Freiesleben N, Gerds TA, Forman JL, Silver JD, Nyboe Andersen A, Popovic-Todorovic B. Risk charts to identify low and excessive responders among first-cycle IVF/ICSI standard patients.
Reproductive biomedicine online. 2011;22:50-8.

La Marca A, Broekmans FJ, Volpe A, Fauser BC, Macklon NS. AntiMullerian hormone (AMH): what do we still need to know? Hum reprod. 2009;24:2264-75.

La Marca A, Papaleo E, Grisendi V, Argento C, Giulini S, Volpe A. Development of a nomogram based on markers of ovarian reserve for the individualisation of the follicle-stimulating hormone starting dose in in vitro fertilisation cycles. BJOG : an international journal of obstetrics and gynaecology. 2012.

La Marca A, Sighinolfi G, Radi D, Argento C, Baraldi E, Artenisio AC, Stabile $G$, Volpe A. Anti-Mullerian hormone (AMH) as a predictive marker in assisted reproductive technology (ART). Hum Reprod Update. 2010;16:113-30.

La Marca A, Stabile G, Artenisio AC, Volpe A. Serum anti-Mullerian hormone throughout the human menstrual cycle. Hum reprod. 2006;21:3103-7.

Lekamge DN, Barry M, Kolo M, Lane M, Gilchrist RB, Tremellen KP. Anti-Mullerian hormone as a predictor of IVF outcome. Reproductive biomedicine online. 2007;14:602-10.

Martinez-Conejero JA, Simon C, Pellicer A, Horcajadas JA. Is ovarian stimulation detrimental to the endometrium? Reproductive biomedicine online. 2007;15:45-50.

Muttukrishna S, McGarrigle H, Wakim R, Khadum I, Ranieri DM, Serhal P. Antral follicle count, anti-mullerian hormone and inhibin B: predictors of ovarian response in assisted reproductive technology? BJOG : an international journal of obstetrics and gynaecology. 2005;112:1384-90.

Nakhuda GS, Douglas NC, Thornton MH, Guarnaccia MM, Lobo R, Sauer MV. Anti-Mullerian hormone testing is useful for individualization of stimulation protocols in oocyte donors. Reproductive biomedicine online. 2010;20:42-7.

Nelson SM, Anderson RA, Broekmans FJ, Raine-Fenning N, Fleming $\mathrm{R}$, La Marca A. Anti-Mullerian hormone: clairvoyance or crystal clear? Hum reprod. 2012;27:631-6.

Nelson SM, La Marca A. The journey from the old to the new AMH assay: how to avoid getting lost in the values. Reproductive biomedicine online. 2011;23:411-20.

Nelson SM, Yates RW, Lyall H, Jamieson M, Traynor I, Gaudoin M, Mitchell P, Ambrose P, Fleming R. Anti-Mullerian hormone-based approach to controlled ovarian stimulation for assisted conception. Hum reprod. 2009;24:867-75.

Nikolaou D, Templeton A. Early ovarian ageing: a hypothesis. Detection and clinical relevance. Hum reprod. 2003;18:1137-9.

Queenan JT, Jr., Whiman-Elia G. An appreciation of modern ART. Clin obstet and gynecol. 2000;43:942-57.

Riggs RM, Duran EH, Baker MW, Kimble TD, Hobeika E, Yin L, MatosBodden $L$, Leader B, Stadtmauer L. Assessment of ovarian reserve with anti-Mullerian hormone: a comparison of the predictive value of anti-Mullerian hormone, follicle-stimulating hormone, inhibin B, and age. Am j obstet and gynecol. 2008;199:202 e1-8.

Rombauts L, Onwude JL, Chew HW, Vollenhoven BJ. The predictive value of antral follicle count remains unchanged across the menstrual cycle. Fertil and steril. 2011;96:1514-8.

Rubio C, Mercader A, Alama P, Lizan C, Rodrigo L, Labarta E, Melo $M$, Pellicer A, Remohi J. Prospective cohort study in high responder oocyte donors using two hormonal stimulation protocols: impact on embryo aneuploidy and development. Hum reprod. 2010;25:22907.

Spencer JB, Browne AS, Copland SD, Session DR. Discontinuation of rLH two days before hCG may increase the number of oocytes retrieved in IVF. RB\&E. 2010;8:29.

van Disseldorp J, Lambalk CB, Kwee J, Looman CW, Eijkemans MJ, Fauser BC, Broekmans FJ. Comparison of inter- and intra-cycle variability of anti-Mullerian hormone and antral follicle counts. Hum reprod. 2010;25:221-7.

Wang JG, Douglas NC, Nakhuda GS, Choi JM, Park SJ, Thornton MH, Guarnaccia MM, Sauer MV. The association between antiMullerian hormone and IVF pregnancy outcomes is influenced by age. Reproductive biomedicine online. 2010;21:757-61.

Yates AP, Rustamov O, Roberts SA, Lim HY, Pemberton PW, Smith A, Nardo LG. Anti-Mullerian hormone-tailored stimulation protocols improve outcomes whilst reducing adverse effects and costs of IVF. Hum reprod. 2011;26:2353-62.

Younis JS, Jadaon J, Izhaki I, Haddad S, Radin O, Bar-Ami S, Ben-Ami M. A simple multivariate score could predict ovarian reserve, as well as pregnancy rate, in infertile women. Fertility and sterility. 2010;94:655-61.

Yovich J, Stanger J, Hinchliffe P. Targeted gonadotrophin stimulation using the PIVET algorithm markedly reduces the risk of OHSS. Reproductive biomedicine online. 2012;24:281-92. 